\title{
The uncalibrated pulse contour cardiac output during off- pump coronary bypass surgery: performance in patients with a low cardiac output status and a reduced left ventricular function
}

\author{
Youn Yi Jo ${ }^{1}$, Jong Wook Song ${ }^{2}$, Young Chul Yoo ${ }^{2}$, Ji Young Park², Jae Kwang Shim², and Young Lan Kwak ${ }^{2}$ \\ ${ }^{1}$ Department of Anesthesiology and Pain Medicine, Gachon University of Medicine and Science, Gil Medical Center, Incheon, \\ ${ }^{2}$ Anesthesia and Pain Research Institute, Yonsei University College of Medicine, Seoul, Korea
}

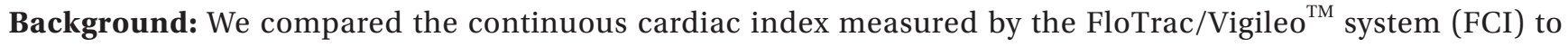
that measured by a pulmonary artery catheter (CCI) with emphasis on the accuracy of the FCI in patients with a decreased left ventricular ejection fraction (LVEF) and a low cardiac output status during off-pump coronary bypass surgery (OPCAB). We also assessed the influence of several factors affecting the pulse contour, such as the mean arterial pressure (MAP), the systemic vascular resistance index (SVRI) and the use of norepinephrine.

Methods: Fifty patients who were undergoing OPCAB (30 patients with a LVEF $\geq 40 \%, 20$ patients with a LVEF $<40 \%$ ) were enrolled. The FCI and CCI were measured and we performed a Bland-Altman analysis. Subgroup analyses were done according to the $\operatorname{LVEF}(<40 \%)$, the CCI $(\leq 2.4 \mathrm{~L} / \mathrm{min} / \mathrm{m})$, the MAP $(60-80 \mathrm{mmHg})$, the SVRI $(1,600-2,600$ dyne $/ \mathrm{s} / \mathrm{cm}^{5} / \mathrm{m}^{2}$ ) and the use of norepinephrine.

Results: The FCI was reliable at all the time points of measurement with an overall bias and limit of agreement of -0.07 and $0.67 \mathrm{~L} / \mathrm{min} / \mathrm{m}^{2}$, respectively, resulting in a percentage error of $26.9 \%$. The percentage errors in the patients with a decreased LVEF and in a low cardiac output status were $28.2 \%$ and $22.3 \%$, respectively. However, the percentage error in the 91 data pairs outside the normal range of the SVRI was $40.2 \%$.

Conclusions: The cardiac output measured by the FloTrac/Vigileo ${ }^{\mathrm{TM}}$ system was reliable even in patients with a decreased LVEF and in a low cardiac output status during OPCAB. Acceptable agreement was also noted during the period of heart displacement and grafting of the obtuse marginalis branch. (Korean J Anesthesiol 2011; 60: 237-243)

Key Words: Cardiac output, Measurement techniques, Off pump coronary artery bypass.

Received: July 19, 2010. Revised: October 8, 2010. Accepted: October 26, 2010.

Corresponding author: Jae Kwang Shim, M.D., Ph.D., Department of Anesthesiology and Pain Medicine, Anesthesia and Pain Research Institute, Yonsei University Health System, 250, Seongsan-no, Seodaemun-gu, Seoul 120-752, Korea. Tel: 82-2-2228-8513, Fax: 82-2-364-2951,

E-mail: aneshim@yuhs.ac

This study is supported by a faculty research grant of Yonsei University College of medicine of 2007 (6-2007-0140).

@ This is an open-access article distributed under the terms of the Creative Commons Attribution Non-Commercial License (http:// creativecommons.org/licenses/by-nc/3.0/), which permits unrestricted non-commercial use, distribution, and reproduction in any medium, provided the original work is properly cited. 


\section{Introduction}

Estimating the cardiac output constitutes an essential part of the hemodynamic monitoring during cardiac surgery as it provides the basis for therapeutic interventions to ensure adequate tissue perfusion. For that purpose, a pulmonary artery catheter (PAC) using the thermodilution method has been considered a 'clinical standard' along with its attendant limitations [1]. The invasive nature of the PAC carries the risk of various complications, including damage to the cardiac valves and pulmonary artery rupture, and the clinical value of the data obtained from the PAC remains a matter of heated debate [2].

The FloTrac/Vigileo ${ }^{\text {TM }}$ system (Edwards Lifesciences, Irvine, CA, USA) is a less invasive method of acquiring continuous data on the cardiac output and this system uses pulse contour analysis. It requires only standard radial artery catheterization and it empirically correlates the standard deviation (SD) of the pulse pressure to the stroke volume on the basis of the patient's characteristics after automatic adjustment for actual vascular compliance and thus, it does not require external calibration [3].

The earlier validation studies of the FloTrac/Vigileo ${ }^{\mathrm{TM}}$ system have demonstrated conflicting results [4-7]. With the updated software (version 1.07) that provides a reduced time window ( $1 \mathrm{~min}$ ) for vascular adjustment, the recent clinical studies that focused on cardiac surgeries have demonstrated promising results [8-10]. Still, the evidence regarding its accuracy is limited for surgeries accompanied with changes in the vascular compliance, and especially for patients with a decreased left ventricular ejection fraction (LVEF) and for patients with a low cardiac output status, and accurately estimating the cardiac output is of particular importance for clinical decision making. Furthermore, no comprehensive data exist regarding the influence of factors that affect the pulse contour.

We evaluated the accuracy of the cardiac output measured by the FloTrac/Vigileo ${ }^{\mathrm{TM}}$ system (software version 1.07), as compared to the cardiac output measured by a PAC, in patients who are undergoing off-pump coronary bypass surgery (OPCAB), and we included patients with a decreased LVEF. We also evaluated the influence of the mean arterial pressure (MAP), the systemic vascular resistance index (SVRI) and the use of vasopressor on the performance of the FloTrac/Vigileo ${ }^{\mathrm{TM}}$ system.

\section{Materials and Methods}

This study was approved by the Institutional Review Board of our hospital and written informed consent was obtained from all subjects. The study subjects were 50 patients (30 patients with LVEF $\geq 40 \%$, 20 patients with LVEF $<40 \%$ ) who were scheduled for elective, isolated, multivessel OPCAB between June 2007 and February 2008. The LVEF was measured with transthoracic echocardiography and using the biplane modified Simpson's method 1 day prior to surgery by cardiologists who were not aware of this study. The patients with preexisting pulmonary disease, concomitant valvular heart disease, cardiac arrhythmias and peripheral vascular disease were excluded from the study.

The patients' cardiac medications were continued until the morning of the surgery, except for diuretics and antiplatelet agents. All the patients received $0.05-0.1 \mathrm{mg} / \mathrm{kg}$ of morphine intramuscularly as premedication $1 \mathrm{hr}$ before their operation. Upon arrival at the operating room, standard monitoring devices were applied including a PAC (Swan-Ganz CCOmbo $\mathrm{CCO} / \mathrm{SvO}_{2}{ }^{\mathrm{TM}}$, Edwards Lifesciences LLC, Irvine, CA, USA), which was inserted via the right internal jugular vein and connected to an analysis system (Vigilance ${ }^{\mathrm{TM}}$, Edwards Lifesciences LLC, Irvine, CA, USA) for continuous monitoring of the cardiac index (CCI) and the mixed venous oxygen saturation $\left(\mathrm{SvO}_{2}\right)$. The radial artery was also cannulated in all the patients with a 20-G cannula (BD Angiocath Plus ${ }^{\mathrm{TM}}$, Becton Dickinson Korea Ltd. Korea) and this was connected to a FloTrac/Vigileo ${ }^{\mathrm{TM}}$ sensor for estimating the continuous arterial pressure waveform analysis cardiac index (FCI). All the transducers were zeroed at the mid-axillary level and care was taken to ensure that the pressure waveform was not dampened during the study period. Anesthesia was induced with intravenous midazolam (0.03$0.07 \mathrm{mg} / \mathrm{kg}$ ) and sufentanil $(1.5-2.0 \mu \mathrm{g} / \mathrm{kg})$, and anesthesia was maintained with sevoflurane $(0.8-1.5 \%)$ and a continuous infusion of sufentanil $(0.5-1.5 \mu \mathrm{g} / \mathrm{kg} / \mathrm{hr})$. Neuromuscular blockade was achieved by administering rocuronium (0.9 mg/ $\mathrm{kg}$ ) and this was maintained with a continuous infusion of vecuronium $(1-2 \mu \mathrm{g} / \mathrm{kg} / \mathrm{min})$. Isosorbide dinitrate $0.5 \mu \mathrm{g} / \mathrm{kg} /$ min was infused in all the patients throughout the study period. The patients' lungs were ventilated with a tidal volume of $8-10$ $\mathrm{ml} / \mathrm{kg}$, with an $\mathrm{I}: \mathrm{E}$ ratio of $1: 2$, at a rate of $8-12$ breaths $/ \mathrm{min}$ of $40 \%$ oxygen with air and a positive end-expiratory pressure of 5 $\mathrm{cmH}_{2} \mathrm{O}$ during the surgery. Intravascular volume replacement was managed with crystalloid and colloid solutions to maintain the pulmonary capillary wedge pressure between $8-16 \mathrm{mmHg}$ according to the baseline values prior to manipulation of the heart and after completion of grafting. During the period of heart displacement, the crystalloid solution was infused at a fixed rate of $6-8 \mathrm{ml} / \mathrm{kg} / \mathrm{hr}$, whereas the colloid solution was infused to compensate for the amount of blood loss collected by a cell salvage device. The blood salvaged by the cell salvage device was reinfused to the patient before the end of the surgery. The hemodynamic management was as follows; 1) maintenance of the MAP between $60-80 \mathrm{mmHg}$ with either a norepinephrine or nicardipine infusion with a $10-20^{\circ}$ Trendelenburg position and/or a norepinephrine infusion during heart displacement), 2) infusion of milrinone in the patients with a $\mathrm{SvO}_{2}<60 \%$ for longer 
than $10 \mathrm{~min}$ and/or the development of mitral regurgitation $\geq$ grade 3 with a concomitant rise of the mean pulmonary arterial pressure $>30 \mathrm{mmHg}$. Allogenic packed red blood cells were transfused when the hematocrit level was $<25 \%$ throughout the study period. The central temperature, as measured by the $\mathrm{PAC}$, was maintained between $36-37^{\circ} \mathrm{C}$ with a warm mattress, a forced warm air blanket and fluid warmer as necessary.

All the surgical procedures were performed by one surgeon through a median sternotomy and the heart was displaced using posterior pericardial stitches, large $(12 \times 70 \mathrm{~cm})$ gauze swabs and tissue stabilizer (Octopus Tissue Stabilization System $^{\circledR}$, Medtronic Inc. USA). All the patients were transferred to the intensive care unit after the surgery.

The hemodynamic variables obtained from the PAC and FloTrac/Vigileo ${ }^{\mathrm{TM}}$ system, including the CCI, FCI, $\mathrm{SvO}_{2}$, heart rate (HR), central venous pressure (CVP) and SVRI, were recorded at the following time points: $15 \mathrm{~min}$ after induction of anesthesia (baseline, T1), during Y-graft construction with the opened pericardium and the heart in a neutral position (T2), 5 min after stabilizer application for the obtuse marginalis branch anastomosis (T3), 15 min after completion of grafting with the opened pericardium (T4) and $15 \mathrm{~min}$ after sternum closure (T5). At T3, the average of 3 consecutive STAT mode cardiac index measurements by the PAC was considered as the $\mathrm{CCI}$ and the average of 3 consecutive $20 \mathrm{sec}$ trend cardiac index measurements by the FloTrac/Vigileo ${ }^{\mathrm{TM}}$ system was considered as the FCI. Of the 3 consecutive measurements by both the $\mathrm{PAC}$ and the FloTrac/Vigileo ${ }^{\mathrm{TM}}$ system, the middle values were acquired at $5 \mathrm{~min}$ after applying stabilizer to coincide with the timing of the cardiac output measurement. At the other time points of measurements, the trend for the FCI was set to $5 \mathrm{~min}$. The SVRI was calculated with the CCI.

Statistical analyses were performed using SPSS 12.0 (SPSS Inc., Chicago, IL, USA). All the data is expressed as the number of patients or means \pm SDs. The data was assessed for a normal distribution of variance with the Shapiro-Wilk test. Repeated measurements of ANOVA with the Bonferroni test was used to compare the hemodynamic variables between consecutive measurements. The FCI and CCI were compared using a modified Bland-Altman analysis of agreement for repeated measures, where bias was defined as the average difference between the FCI and CCI values and the limit of agreement was defined as the 2 SDs of the bias $[11,12]$. The percentage error (2 SDs of the bias/mean cardiac index) was calculated according to Critchley and Critchley [13]. A percentage error of $30 \%$ or less was established as the criterion for method interchangeability [13]. Subgroup analyses that compared the FCI and CCI with the same statistical methods were performed according to a LVEF $<40 \%$, and without modification for repeated measures according to a $\mathrm{CCI} \leq 2.4 \mathrm{~L} / \mathrm{min} / \mathrm{m}^{2}$, a MAP of $60-80$ $\mathrm{mmHg}$, a SVRI of $1,600-2,600$ dyne $\mathrm{s} / \mathrm{cm}^{5} / \mathrm{m}^{2}$ and the use of norepinephrine.

\section{Results}

OPCAB could be successfully performed in all 50 patients and a total of 250 data pairs could all be recorded and then analyzed.

Table 1. Patients' Characteristics

\begin{tabular}{lc}
\multicolumn{1}{c}{ Variables } & Value \\
\hline Age (yr) & $64(47-77)$ \\
Gender (male/female) & $38 / 22$ \\
Body surface area $\left(\mathrm{m}^{2}\right)$ & $1.8 \pm 0.2$ \\
LVEF (\%) & $49 \pm 16$ \\
Diabetes mellitus (DM) & 23 \\
Hypertension (HTN) & 30 \\
DM + HTN & 14 \\
Preoperative cardiac medication & 11 \\
Nitrate & 24 \\
Beta blocker & 23 \\
Calcium channel blocker & 26 \\
RAS blocker & \\
\hline
\end{tabular}

Values are medians (range), means (SD) or number of patients. RAS blocker: rennin-angiotensin system antagonist.

Table 2. Hemodynamic Data

\begin{tabular}{|c|c|c|c|c|c|}
\hline & $\mathrm{T} 1$ & $\mathrm{~T} 2$ & $\mathrm{~T} 3$ & $\mathrm{~T} 4$ & T5 \\
\hline HR (beats / min) & $60 \pm 9$ & $62 \pm 10$ & $64 \pm 9$ & $64 \pm 9$ & $66 \pm 9 *$ \\
\hline MAP (mmHg) & $73 \pm 10$ & $73 \pm 7$ & $76 \pm 9$ & $73 \pm 7$ & $76 \pm 7$ \\
\hline CVP (mmHg) & $7 \pm 2$ & $7 \pm 2$ & $9 \pm 3^{*}$ & $8 \pm 3$ & $7 \pm 3$ \\
\hline $\mathrm{SvO}_{2}(\%)$ & $78 \pm 6$ & $76 \pm 6$ & $68 \pm 8^{*}$ & $74 \pm 8$ & $76 \pm 7$ \\
\hline $\mathrm{CCI}\left(\mathrm{L} / \mathrm{min} / \mathrm{m}^{2}\right)$ & $2.8 \pm 0.6$ & $2.7 \pm 0.4$ & $2.1 \pm 0.3^{*}$ & $2.6 \pm 0.5$ & $2.6 \pm 0.5$ \\
\hline $\mathrm{FCI}\left(\mathrm{L} / \mathrm{min} / \mathrm{m}^{2}\right)$ & $2.6 \pm 0.4$ & $2.6 \pm 0.4$ & $2.2 \pm 0.3^{*}$ & $2.5 \pm 0.5$ & $2.6 \pm 0.4$ \\
\hline SVRI (dyne s $/ \mathrm{cm}^{5} / \mathrm{m}^{2}$ ) & $1,956 \pm 549$ & $1,925 \pm 382$ & $2,464 \pm 469 *$ & $2,361 \pm 526$ & $2,264 \pm 543$ \\
\hline
\end{tabular}

The table presents the hemodynamic data. The data is presented as means \pm SDs. T1: 15 min after induction of anesthesia, T2: during Y-graft construction with opened pericardium, T3: 5 min after applying stabilizer for creating an obtuse marginalis branch anastomosis, T4: 15 min after completion of grafting with opened pericardium, T5: $15 \mathrm{~min}$ after sternum closure, HR: heart rate, MAP: mean arterial pressure, CVP: central venous pressure, $\mathrm{SvO}_{2}$ : mixed venous oxygen saturation, CCI: continuous cardiac index measured by a pulmonary artery catheter, FCI: cardiac index measured by the FloTrac/Vigileo ${ }^{\mathrm{TM}}$ system, SVRI: systemic vascular resistance index. $* \mathrm{P}<0.05$ compared to the values at T1. 
The patients' characteristics are listed in Table 1. All the patients were in normal sinus rhythm throughout the study period.

The hemodynamic data is listed in Table 2. The CVP and SVRI were significantly increased, and the $\mathrm{SvO}_{2}$, CCI and FCI were all significantly decreased at $\mathrm{T} 3$ compared to each baseline value.

Overall, the CCI and FCI values were $2.7 \pm 0.5 \mathrm{~L} / \mathrm{min} / \mathrm{m}^{2}$ (range: $1.4-4.5$ ) and $2.6 \pm 0.4 \mathrm{~L} / \mathrm{min} / \mathrm{m}^{2}$ (range: $1.6-4.1$ ), respectively. Bland-Altman analysis of the FCI and CCI values demonstrated an overall mean bias and a limit of agreement of -0.07 and 0.67 $\mathrm{L} / \mathrm{min} / \mathrm{m}^{2}$, respectively, resulting in a percentage error of $26.9 \%$. The bias, limit of agreement and percentage error at various predefined time points of measurement were all acceptable.
(Table 3, Fig. 1).

The results of the subgroup analyses according to the LVEF, CCI, MAP, SVRI and norepinephrine use are listed in Table 4 and Fig 1 . The data pairs of the patients with a decreased LVEF $\left(<40 \%\right.$ ) or $\mathrm{CCI} \leq 2.4 \mathrm{~L} / \mathrm{min} / \mathrm{m}^{2}$ all demonstrated a percentage error of $<30 \%$. The data pairs divided according to a MAP of 60-80 $\mathrm{mmHg}$ and norepinephrine use also demonstrated a percentage error of $<30 \%$. However, the data pairs of a SVRI of either $<1,600$ or $>2,600$ dyne $\mathrm{s} / \mathrm{cm}^{5} / \mathrm{m}^{2}$ demonstrated a percentage error of $40.2 \%$ in contrast to the percentage error of $15.5 \%$ for the data pairs of a SVRI between 1,600 and 2,600 dyne $\mathrm{s} / \mathrm{cm}^{5} / \mathrm{m}^{2}$.

Table 3. Bland-Altman Analyses of the Cardiac Index

\begin{tabular}{lcccccc}
\hline & T1 & T2 & T3 & T4 & T5 & Total \\
\hline Bias $\left(\mathrm{L} / \mathrm{min} / \mathrm{m}^{2}\right)$ & -0.23 & -0.12 & 0.10 & -0.05 & -0.08 & -0.07 \\
Limit of agreement $\left(\mathrm{L} / \mathrm{min} / \mathrm{m}^{2}\right)$ & 0.78 & 0.52 & 0.56 & 0.60 & 0.60 & 0.67 \\
\% error & 28.9 & 19.6 & 26.4 & 23.5 & 24.1 & 26.9 \\
\hline
\end{tabular}

The table presents the Bland-Altman analyses of the cardiac index as measured by the FloTrac/Vigileo ${ }^{\mathrm{TM}}$ system and the pulmonary artery catheter. T1: 15 min after induction of anesthesia, T2: during Y-graft construction with opened pericardium, T3: 5 min after applying stabilizer for creating an obtuse marginalis branch anastomosis, T4: $15 \mathrm{~min}$ after completion of grafting with opened pericardium, T5: 15 min after sternum closure.

A

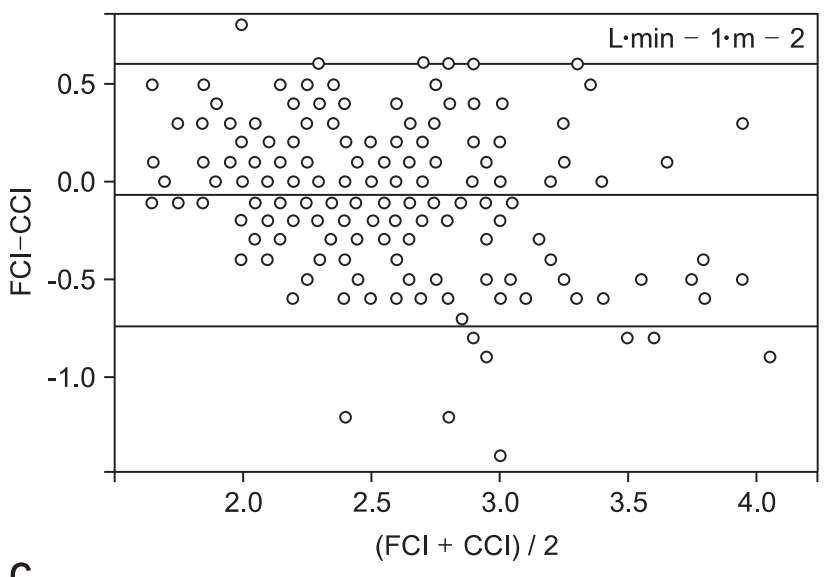

C

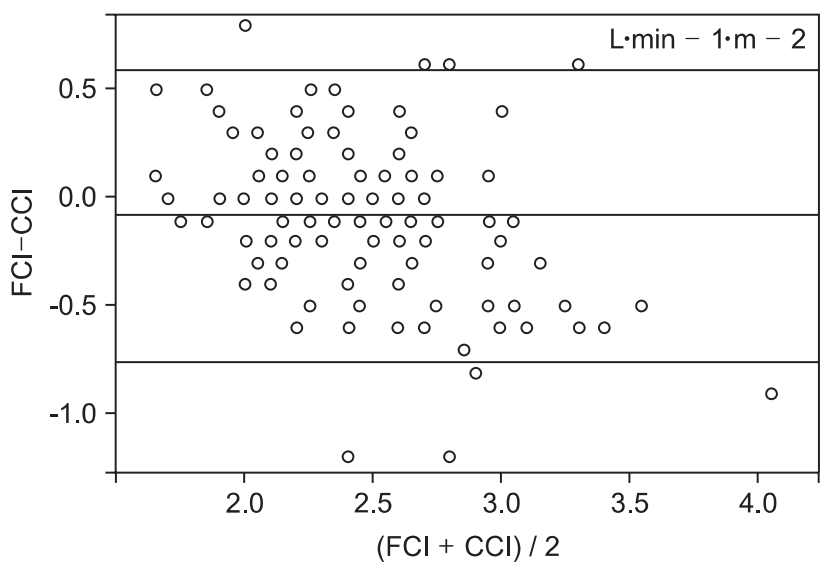

B

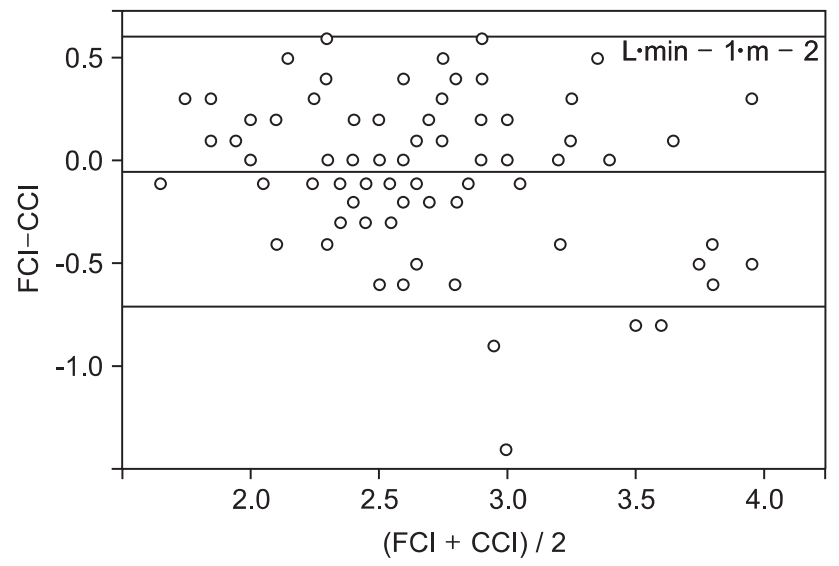

Fig. 1. Modified Bland-Altman analysis for repeated measures of agreement between the continuous cardiac index as measured by the FloTrac/Vigileo ${ }^{\mathrm{TM}}$ system (FCI) and a pulmonary artery catheter (CCI). (A) Overall, 250 data pairs, (B) 20 patients with a left ventricular ejection fraction $<40 \%, 100$ data pairs, (C) 30 patients with left ventricular ejection fraction $\geq 40 \%, 150$ data pairs. The unit of bias and the limit of agreement are $\mathrm{L} / \mathrm{min} / \mathrm{m}^{2}$. 
Table 4. Subgroup Bland-Altman Analyses of the Cardiac Index

\begin{tabular}{|c|c|c|c|c|c|c|}
\hline & & FCI & CCI & Bias & Limit of agreement & $\%$ error \\
\hline \multirow{2}{*}{ LVEF } & $\geq 40(\mathrm{n}=150)$ & $2.6 \pm 0.4$ & $2.7 \pm 0.5$ & -0.05 & 0.66 & 25.2 \\
\hline & $<40(\mathrm{n}=100)$ & $2.4 \pm 0.4$ & $2.5 \pm 0.4$ & -0.09 & 0.67 & 28.2 \\
\hline \multirow[t]{2}{*}{ CCI } & $>2.4(\mathrm{n}=135)$ & $2.7 \pm 0.4$ & $2.9 \pm 0.4$ & -0.19 & 0.70 & 25.3 \\
\hline & $\leq 2.4(\mathrm{n}=115)$ & $2.2 \pm 0.3$ & $2.2 \pm 0.2$ & 0.08 & 0.48 & 22.3 \\
\hline \multirow[t]{2}{*}{ MAP } & $60-80(\mathrm{n}=207)$ & $2.4 \pm 0.4$ & $2.6 \pm 0.5$ & -0.12 & 0.61 & 24.8 \\
\hline & $<60$ or $>80(\mathrm{n}=43)$ & $2.7 \pm 0.5$ & $2.5 \pm 0.5$ & 0.14 & 0.77 & 30.0 \\
\hline \multirow[t]{2}{*}{ SVRI } & $1,600-2,600(\mathrm{n}=159)$ & $2.5 \pm 0.4$ & $2.5 \pm 0.3$ & -0.06 & 0.38 & 15.5 \\
\hline & $<1,600$ or $>2,600(\mathrm{n}=91)$ & $2.5 \pm 0.5$ & $2.6 \pm 0.7$ & -0.09 & 1.01 & 40.2 \\
\hline \multirow[t]{2}{*}{ NE } & Not used $(n=137)$ & $2.5 \pm 0.4$ & $2.6 \pm 0.5$ & -0.11 & 0.71 & 27.8 \\
\hline & Used (n=113) & $2.4 \pm 0.5$ & $2.5 \pm 0.5$ & -0.03 & 0.61 & 25.3 \\
\hline
\end{tabular}

The table presents the subgroup Bland-Altman analyses of the cardiac index as measured by the FloTrac/Vigileo ${ }^{\mathrm{TM}}$ system $\left(\mathrm{FCI}, \mathrm{L} / \mathrm{min} / \mathrm{m}^{2}\right)$ and the pulmonary artery catheter (CCI, L/min $/ \mathrm{m}^{2}$ ) according to the left ventricular ejection fraction (LVEF, \%), the CCI, the mean arterial pressure (MAP, mmHg), the systemic vascular resistance index (SVRI, dyne $\cdot \mathrm{s} / \mathrm{cm}^{5} / \mathrm{m}^{2}$ ) and the use of norepinephrine (NE). $\mathrm{n}$ corresponds to the number of obtained data sets. FCI and CCI are presented as means \pm SDs. The unit of bias and the limit of agreement $\operatorname{are~} \mathrm{L} / \mathrm{min} / \mathrm{m}^{2}$.

None of the patients required a nicardipine or milrinone infusion during the study period.

\section{Discussion}

This prospective trial evaluated the accuracy of the FloTrac/ Vigileo $^{\text {TM }}$ system-derived cardiac output in patients who were undergoing $\mathrm{OPCAB}$, and we found clinically acceptable agreement between the FCI and CCI and even for the patients with a decreased LVEF or a low cardiac output status. The agreement was acceptable regardless of the MAP or the use of norepinephrine, except that the agreement was unacceptable (40.2\%) when the SVRI was out of the normal range.

Accurate determining the cardiac output constitutes an important axis of hemodynamic monitoring by providing the basis for guiding therapy to ensure adequate tissue perfusion, and especially in cardiac surgical patients. While the thermodilution method using the PAC with its attendant limitations is currently considered as a clinical standard, less invasive methods using arterial pressure waveform analysis are being extensively studied for their clinical feasibility [3-

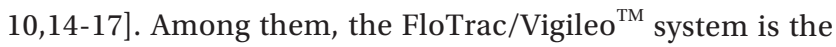
least invasive method because it does not require central venous access for external calibration to compensate for the interindividual differences in aortic compliance [3]. The SD of the pulse pressure is correlated to the stroke volume after adjustment for vascular compliance, which is estimated using the individual demographic data and the wave form characteristics such as skewness and kurtosis. Therefore, the operator dependency is minimized and the drift phenomena may be eliminated by automatic adjustment for the changes in the vascular tone. Yet the benefit of being less invasive provides a potential source to increased bias, and so this decreases the accuracy of the measured cardiac output. Indeed, earlier validation studies have demonstrated conflicting results with acceptable accuracy observed mostly in patients with hemodynamically stable conditions [4-7].

With the improved algorithm of the FloTrac/Vigileo ${ }^{\mathrm{TM}}$ system (software version 1.07), the rate of adjustment of the internal variables for estimating the vascular tone is reduced from 10 to 1 minutes combined with a reduction of the pulse wave detection noise. Validation studies of this second generation device have demonstrated more consistent results in cardiac surgeries with good agreement for the OPCAB and cardiac surgeries that are done under cardiopulmonary bypass as well [8-10]. However, none of the previous studies used a modified Bland-Altman analysis of agreement for repeated measures, and the cardiac output in the previous studies was measured and compared at multiple time points from each patient. Moreover, the previously reported evidence is limited regarding the accuracy of the cardiac output, as measured by the FloTrac/Vigileo ${ }^{\mathrm{TM}}$ system, in patients with a decreased LVEF and in those patients with a lower than normal or low cardiac output status, which is when accurate estimation of the cardiac output is especially required to decide whether therapies targeted to improve oxygen delivery should be initiated. Moreover, considering that the peripheral arterial pulse wave is the summation of the reflected waves with the fundamental waves determined by the interaction between the left ventricular output and the capacitance of the vascular tree [18], abnormal ranges of the MAP and SVRI and the use of vasopressors could all be potential sources of error in the pulse contour analysis-derived cardiac output measurement. Yet no comprehensive data exist regarding the influence of these factors on the accuracy of the cardiac output measured by the FloTrac/Vigileo ${ }^{\mathrm{TM}}$ system.

The results of this current trial indicate that the cardiac output measured by the FloTrac/Vigileo ${ }^{\mathrm{TM}}$ system consistently demonstrated good agreement with a percentage error $\leq 30 \%$ 
at various time points of measurements during OPCAB. Good agreement could also be demonstrated in the patients with a decreased LVEF $(<40 \%)$ and at time points of a decreased CCI $\left(\leq 2.4 \mathrm{~L} / \mathrm{min} / \mathrm{m}^{2}\right)$, including the period of heart displacement for obtuse marginalis artery grafting when the hemodynamic derangement is most severe [19]. This seems to be attributable to the improved algorithm of the FloTrac/Vigileo ${ }^{\mathrm{TM}}$ system that attenuates the bias induced by the hemodynamic changes that accompany various surgical situations such as sternotomy, opened pericardium, heart displacement and cumulative ischemia-reperfusion injury of various degrees.

It is interesting to note was that the FloTrac/Vigileo ${ }^{\mathrm{TM}}$ system performed well regardless of the range of the MAP or the use of vasopressor. However, in contrast to the best agreement (percentage error: 15.5\%) demonstrated when the SVRI was within the normal range, the accuracy of the cardiac output measured by the FloTrac/Vigileo ${ }^{\mathrm{TM}}$ system was poor with unacceptable agreement (percentage error: 40.2\%) when the SVRI was outside the normal range. Unacceptable agreement had previously been demonstrated in a study of patients with liver cirrhosis and who were undergoing liver transplantation with a low SVRI [20]. FCI has also been demonstrated to be unreliable when phenylephrine was administered $[21,22]$. However, in those previous studies, phenylephrine administration increased the MAP to $82-90 \mathrm{mmHg}$, while the mean MAP could be maintained between $73-76 \mathrm{mmHg}$ in the current study. Although the SVRI was not calculated in both of the previous studies, an increase in the MAP in our study was accompanied by a decrease in the CCI, suggesting a significant increase in afterload and thus the SVRI over the normal range. It seems that the extent of vasodilation or vasoconstriction, as manifested by extreme ranges of the SVRI, has the most influential impact on the arterial pressure waveform [23], regardless of the MAP or the use of vasopressor. Yet it is difficult to compare and state that this poor performance for a SVRI outside the normal range is a consistent finding since the data regarding this matter is limited at best. In order to improve the device's performance, this issue should also be addressed and incorporated when developing a more refined algorithm for the FloTrac/Vigileo ${ }^{\mathrm{TM}}$ system.

In this study, the FCI was compared to the CCI and not with the cardiac index measured by intermittent PAC thermodilution, which could be a limitation. However, numerous studies have validated the accuracy of the CCI as compared to intermittent PAC thermodilution and even to electromagnetic measurement of the aortic blood flow, which is considered the 'gold standard' in cardiac laboratories [24,25]. Moreover, one of the benefits of the FloTrac/Vigileo ${ }^{\mathrm{TM}}$ system is the minimized operator dependency, which is not the case for the intermittent PAC thermodilution method. Indeed, the variation between two series of three intermittent thermodilution cardiac output measurements is still as high as $15 \%$, and in that regard the CCI has better reproducibility with negligible bias and so it is the less operator-dependent method [26]. The CCI value is an average made over 3-8 minutes of time and when the trend of the FloTrac/Vigileo ${ }^{\mathrm{TM}}$ system is set to 5 minutes, it would be more ideal to compare the FCI to the CCI rather than comparing the FCI to the cardiac output as measured by the intermittent PAC thermodilution method. Likewise, since the response time of the STAT mode of the PAC to changes in the cardiac output has been demonstrated to be approximately 270 seconds [27], we used the STAT mode at T3 to minimize a potential source of error.

In conclusion, the cardiac output measured by the FloTrac/ Vigileo $^{\mathrm{TM}}$ system was reliable even in patients with a decreased LVEF and who were in low cardiac output status during OPCAB. The modified algorithm appears to be robust in various situations of hemodynamic changes such as during the period of heart displacement and also regardless of the use of vasopressor. However, additional refinement of the algorithm should be done to improve the reliability when the SVRI is outside the normal range.

\section{References}

1. Jhanji S, Dawson J, Pearse RM. Cardiac output monitoring: basic science and clinical application. Anaesthesia 2008; 63: 172-81.

2. Sandham JD, Hull RD, Brant RF, Knox L, Pineo GF, Doig CJ, et al. Canadian Critical Care Clinical Trials Group. A randomized, controlled trial of the use of pulmonary-artery catheters in high-risk surgical patients. N Engl J Med 2003; 348: 5-14.

3. Manecke GR. Edwards FloTrac sensor and Vigileo monitor: easy, accurate, reliable cardiac output assessment using the arterial pulse wave. Expert Rev Med Devices 2005; 2: 523-7.

4. Sander M, Spies CD, Grubitzsch H, Foer A, Müller M, von Heymann C. Comparison of uncalibrated arterial waveform analysis in cardiac surgery patients with thermodilution cardiac output measurements. Crit Care 2006; 10: R164.

5. Mayer J, Boldt J, Schöllhorn T, Röhm KD, Mengistu AM, Suttner S. Semi-invasive monitoring of cardiac output by a new device using arterial pressure waveform analysis: a comparison with intermittent pulmonary artery thermodilution in patients undergoing cardiac surgery. Br J Anaesth 2007; 98: 176-82.

6. de Waal EE, Kalkman CJ, Rex S, Buhre WF. Validation of a new arterial pulse contour-based cardiac output device. Crit Care Med 2007; 35: 1904-9.

7. Manecke GR Jr, Auger WR. Cardiac output determination from the arterial pressure wave: clinical testing of a novel algorithm that does not require calibration. J Cardiothorac Vasc Anesth 2007; 21: 3-7.

8. Button D, Weibel L, Reuthebuch O, Genoni M, Zollinger A, Hofer CK. Clinical evaluation of the FloTrac/Vigileo system and two established continuous cardiac output monitoring devices in patients undergoing cardiac surgery. Br J Anaesth 2007; 99: 329-36. 
9. Mayer J, Boldt J, Wolf MW, Lang J, Suttner S. Cardiac output derived from arterial pressure waveform analysis in patients undergoing cardiac surgery: validity of a second generation device. Anesth Analg 2008; 106: 867-72.

10. Mehta Y, Chand RK, Sawhney R, Bhise M, Singh A, Trehan N. Cardiac output monitoring: comparison of a new arterial pressure waveform analysis to the bolus thermodilution technique in patients undergoing off-pump coronary artery bypass surgery. J Cardiothorac Vasc Anesth 2008; 22: 394-9.

11. Bland JM, Altman DG. Statistical methods for assessing agreement between two methods of clinical measurement. Lancet 1986; 1: 307 10.

12. Myles PS, Cui J. Using the Bland-Altman method to measure agreement with repeated measures. Br J Anaesth 2007; 99: 309-11.

13. Critchley LA, Critchley JA. A meta-analysis of studies using bias and precision statistics to compare cardiac output measurement techniques. J Clin Monit Comput 1999; 15: 85-91.

14. Østergaard M, Nielsen J, Nygaard E. Pulse contour cardiac output: an evaluation of the FloTrac method. Eur J Anaesthesiol 2009; 26 : 484-9.

15. Halvorsen PS, Espinoza A, Lundblad R, Cvancarova M, Hol PK, Fosse E, et al. Agreement between PiCCO pulse-contour analysis, pulmonal artery thermodilution and transthoracic thermodilution during off-pump coronary artery by-pass surgery. Acta Anaesthesiol Scand 2006; 50: 1050-7.

16. de Waal EE, Wappler F, Buhre WF. Cardiac output monitoring. Curr Opin Anaesthesiol 2009; 22: 71-7.

17. Chakravarthy M, Rajeev S, Jawali V. Cardiac index value measurement by invasive, semi-invasive and non invasive techniques: a prospective study in postoperative off pump coronary artery bypass surgery patients. J Clin Monit Comput 2009; 23: 175-80.

18. O'Rourke MF, Yaginuma T. Wave reflections and the arterial pulse.
Arch Intern Med 1984; 144: 366-71.

19. Chassot PG, van der Linden P, Zaugg M, Mueller XM, Spahn DR. Off-pump coronary artery bypass surgery: physiology and anaesthetic management. Br J Anaesth 2004; 92: 400-13.

20. Biais M, Nouette-Gaulain K, Cottenceau V, Vallet A, Cochard JF, Revel P, et al. Cardiac output measurement in patients undergoing liver transplantation: pulmonary artery catheter versus uncalibrated arterial pressure waveform analysis. Anesth Analg 2008; 106: 1480-6.

21. Lorsomradee S, Lorsomradee SR, Cromheecke S, De Hert SG. Continuous cardiac output measurement: arterial pressure analysis versus thermodilution technique during cardiac surgery with cardiopulmonary bypass. Anaesthesia 2007; 62: 979-83.

22. Lorsomradee S, Lorsomradee S, Cromheecke S, De Hert SG. Uncalibrated arterial pulse contour analysis versus continuous thermodilution technique: effects of alterations in arterial waveform. J Cardiothorac Vasc Anesth 2007; 21: 636-43.

23. Watt TB Jr, Burrus CS. Arterial pressure contour analysis for estimating human vascular properties. J Appl Physiol 1976; 40: 171-6.

24. Mihaljevic T, von Segesser LK, Tönz M, Leskosek B, Seifert B, Jenni $\mathrm{R}$, et al. Continuous versus bolus thermodilution cardiac output measurements--a comparative study. Crit Care Med 1995; 23: 944-9.

25. Hogue CW Jr, Rosenbloom M, McCawley C, Lappas DG. Comparison of cardiac output measurement by continuous thermodilution with electromagnetometry in adult cardiac surgical patients. J Cardiothorac Vasc Anesth 1994; 8: 631-5.

26. Robin E, Costecalde M, Lebuffe G, Vallet B. Clinical relevance of data from the pulmonary artery catheter. Crit Care 2006; 10 Suppl 3: S3.

27. Lazor MA, Pierce ET, Stanley GD, Cass JL, Halpern EF, Bode RH Jr. Evaluation of the accuracy and response time of STAT-mode continuous cardiac output. J Cardiothorac Vasc Anesth 1997; 11: 432-6. 